\title{
Other Acute Inpatient Hospital
}

National Cancer Institute

\section{Source}

National Cancer Institute. Other Acute Inpatient Hospital. NCI Thesaurus. Code C154426.

An inpatient acute-care hospital not elsewhere specified. 